\title{
Article \\ Diagnostic Yield of Endoscopic Ultrasound-Guided Liver Biopsy in Comparison to Percutaneous Liver Biopsy: A Two-Center Experience
}

\author{
Antonio Facciorusso ${ }^{1}\left(\mathbb{D}\right.$, Daryl Ramai ${ }^{2}$, Maria Cristina Conti Bellocchi $\left.{ }^{3}{ }^{(}\right)$, Laura Bernardoni ${ }^{3}$, Erminia Manfrin ${ }^{4}$, \\ Nicola Muscatiello ${ }^{1}$ and Stefano Francesco Crinò ${ }^{3, *}$ \\ 1 Gastroenterology Unit, Department of Medical and Surgical Sciences, University of Foggia, 71122 Foggia, \\ Italy; antonio.facciorusso@virgilio.it (A.F.); nicomuscatiello@gmail.com (N.M.) \\ 2 Department of Internal Medicine, The Brooklyn Hospital Center, Brooklyn, New York, NY 11201, USA; \\ dramai@tbh.org \\ 3 Gastroenterology and Digestive Endoscopy Unit, The Pancreas Institute, G.B. Rossi University Hospital, \\ 37134 Verona, Italy; mariacristina.contibellocchi@aovr.veneto.it (M.C.C.B.); \\ laura.bernardoni@aovr.veneto.it (L.B.) \\ 4 Department of Diagnostics and Public Health, G.B. Rossi University Hospital, 37134 Verona, Italy; \\ erminia.manfrin@univr.it \\ * Correspondence: stefanofrancesco.crino@aovr.veneto.it
}

check for updates

Citation: Facciorusso, A.; Ramai, D.; Conti Bellocchi, M.C.; Bernardoni, L.; Manfrin, E.; Muscatiello, N.; Crinò, S.F. Diagnostic Yield of Endoscopic Ultrasound-Guided Liver Biopsy in Comparison to Percutaneous Liver Biopsy: A Two-Center Experience. Cancers 2021, 13, 3062. https:/ / doi.org/10.3390/cancers13123062

Academic Editor: Masaru Miyazaki

Received: 3 May 2021

Accepted: 16 June 2021

Published: 19 June 2021

Publisher's Note: MDPI stays neutral with regard to jurisdictional claims in published maps and institutional affiliations.

Copyright: (c) 2021 by the authors. Licensee MDPI, Basel, Switzerland. This article is an open access article distributed under the terms and conditions of the Creative Commons Attribution (CC BY) license (https:// creativecommons.org/licenses/by/ $4.0 /)$.
Simple Summary: Traditionally, liver biopsy has been performed by percutaneous radiology-guided methods. Advances in endoscopic ultrasound have demonstrated the efficacy of endoscopic based techniques for liver biopsy. Studies comparing both methods are scarce and have conflicting results. Our study compares percutaneous and endoscopic ultrasound methods for liver biopsy. Our analysis shows no evidence to support the wide use of endoscopic ultrasound. Percutaneous liver biopsy remains the sampling method of choice in this field.

Abstract: There is scarce and conflicting evidence on the comparison between endoscopic ultrasound (EUS) and percutaneous (PC)-guided liver biopsy (LB). The aim of this study was to compare the two approaches in a series of patients with parenchymal and focal liver lesions. Fifty-four patients undergoing EUS-LB in two high-volume centers between 2017 and 2021 were compared to 62 patients who underwent PC-LB. The primary outcome was diagnostic adequacy rate. The secondary outcomes were diagnostic accuracy, total sample length (TSL), number of complete portal tracts (CPTs), procedural duration, and adverse events. Variables were compared using the Chi-square and Mann-Whitney test. Median age was 56 years (interquartile range 48-69) in the EUS-LB group and 54 years (45-67) in the PC-LB group with most patients being male. Indication for LB was due to parenchymal disease in $50 \%$ of patients, whereas the other patients underwent LB due to focal liver lesions. Diagnostic adequacy was $100 \%$ in PC-LB and $94.4 \%$ in the EUS-LB group ( $p=0.74)$, whereas diagnostic accuracy was $88.8 \%$ in the EUS-LB group and $100 \%$ in the PC-LB group ( $p=0.82$ ). Median TSL was significantly greater in the PC-LB group (27.4 mm, IQR 21-29) when compared to the EUS-LB group (18.5 mm, 10.1-22.4; $p=0.02)$. The number of complete portal tracts was 21 (11-24) in the PC-LB group and $18.5(10-23.2)$ in EUS-LB group $(p=0.09)$. EUS-LB was a significantly longer procedure (7 $\mathrm{min}, 5-11$ versus $1 \mathrm{~min}, 1-3$ of PC-LB; $p<0.001$ ) and no evidence of adverse events was observed in any of the study groups. These results were confirmed in the subgroup analysis performed according to an indication for LB (parenchymal disease versus focal lesion). Although PC-LB yielded specimens with greater TSL, diagnostic adequacy and accuracy were similar between the two procedures.

Keywords: endoscopic ultrasound; liver biopsy; percutaneous liver biopsy 


\section{Introduction}

Liver biopsy (LB) represents the gold standard in the diagnostic algorithm of several hepatic disorders and focal liver lesions. In fact, although non-invasive testing such as liver stiffness measurement through transient elastography and the improvement in diagnostic tools for focal liver lesions decreased the need for LB [1,2], histologic analysis remains necessary in the case of uncertain diagnoses or when immunohistochemistry is needed.

LB has been commonly performed for years using percutaneous (PC-LB), under CTscan or ultrasonographic (US) guidance, and transjugular (TJ-LB) approaches. However, even in high-volume centers, PC-LB might determine a non-negligible sampling error rate, thus decreasing diagnostic sensitivity of the procedure; furthermore, as usually only the right lobe is accessible for biopsy, focal lesions located in the left lobe could be less easily sampled. Conversely, TJ-LB represents a more complex procedure and potential complications are neck hematoma, vascular injury, arterio-venous fistula, and intra-abdominal hemorrhage [3].

EUS fine-needle aspiration (FNA) and fine-needle biopsy (FNB) are a well-established diagnostic approach and are being employed for years for targeting both focal lesions and parenchymal liver disease $[4,5]$. To this end, many studies evaluating different needles on random liver biopsies have found superior results with FNB compared to FNA [6].

A recent pooled analysis by Mohan et al. reported a histologic diagnostic rate of $93.9 \%$ and adverse event rate of $2.3 \%$ with EUS-guided LB, with better outcomes observed with 19G FNA needles [7]. However, the promising results observed with newer FNB needles, such as the Franseen needle (Acquire ${ }^{\circledR}$ [Boston Scientific, Marlborough, MA, USA]) and the Fork-tip needle (SharkCore ${ }^{\circledR}$ [Medtronic, Dublin, Ireland]), in tissue acquisition of pancreatic masses [8-13] and of subepithelial lesions [14] also require confirmation in the setting of liver biopsy.

Recent studies provided discording evidence on the comparative efficacy of EUS-LB as compared to PC-LB to diagnose parenchymal liver disease. In fact, while previous retrospective studies showed similar results between these two approaches [15-17], a recent small randomized-controlled trial (RCT) suggested better diagnostic performance with PC-LB [18].

Furthermore, no evidence on the comparison between the two procedures for tissue sampling of focal liver lesions is available in the literature.

The aim of our study was to compare EUS-LB and PC-LB in terms of diagnostic outcomes including accuracy and safety in a series of patients with both parenchymal and focal liver disease from two high-volume centers in Italy.

\section{Materials and Methods}

\subsection{Patients}

From a prospectively collected database of 65 patients already undergoing endoscopic ultrasound for different primary EUS indications who would also benefit from a liver biopsy as determined by the referring hepatologist (i.e., abnormal liver function test results, fatty liver disease or suspected focal liver lesions on imaging), data from 54 patients undergoing EUS-guided LB were retrospectively reviewed. Included patients were enrolled in two high-volume Italian centers between 2017 and 2021. Institutional Review Board (IRB) approbation for this retrospective report was obtained.

The following exclusion criteria were used: (1) reluctance to receive EUS-LB or inability to sign informed consent; (2) clear indication for surgical treatment; and (3) coagulopathy (international normalized ratio $>1.5$, platelets $<50,000$ ); concurrent antiaggregant or anticoagulant therapy.

All procedures were performed by two board-certified 10 years-experienced gastroenterologists (N.M. and S.F.C).

To compare these EUS-LB cases with PC-LB, 62 patients with suspected liver parenchymal disease or focal liver lesions sampled through percutaneous approach at our Institu- 
tions between 2015 and 2020 were retrospectively identified. The aforementioned exclusion criteria were applied also to PC-LB patients.

\subsection{EUS-LB}

EUS-LB was performed under general sedation with propofol (Diprivan ${ }^{\circledR}$, AstraZeneca, London, UK) and EUS was conducted with a Pentax EG3870-UTK ultrasound endoscope (Pentax Europe, Ltd., Hamburg, Germany) using a curved-array transducer. No preprocedure antibiotics were administered.

Once in the stomach, the liver was carefully explored and before puncture of the desired lobe, color Doppler imaging was used to ensure the lack of vascular structures or bile ducts in the expected trajectory of the needle. The right and left lobe of the liver were accessed by the transduodenal and transgastric approach, respectively.

Several FNB needles (22G ProCore ${ }^{\circledR}$ [Cook Medical, Bloomington, IN, US], 22G SharkCore ${ }^{\circledR}$, or 22G Acquire ${ }^{\circledR}$ ) and 19G FNA (EchoTip Ultra ${ }^{\circledR}$, Cook Medical LLC, Bloomington, IN, USA) were used; the choice of the needle was left to the individual operator, and in the case of focal liver lesions, the size of the needle was chosen according to the size and the depth of the lesion itself.

Two passes were performed from either lobe of the liver in the case of parenchymal disease, whereas in patients with focal lesions, the need for additional passes was decided according to the macroscopic appearance of the collected material (Figures 1 and 2).

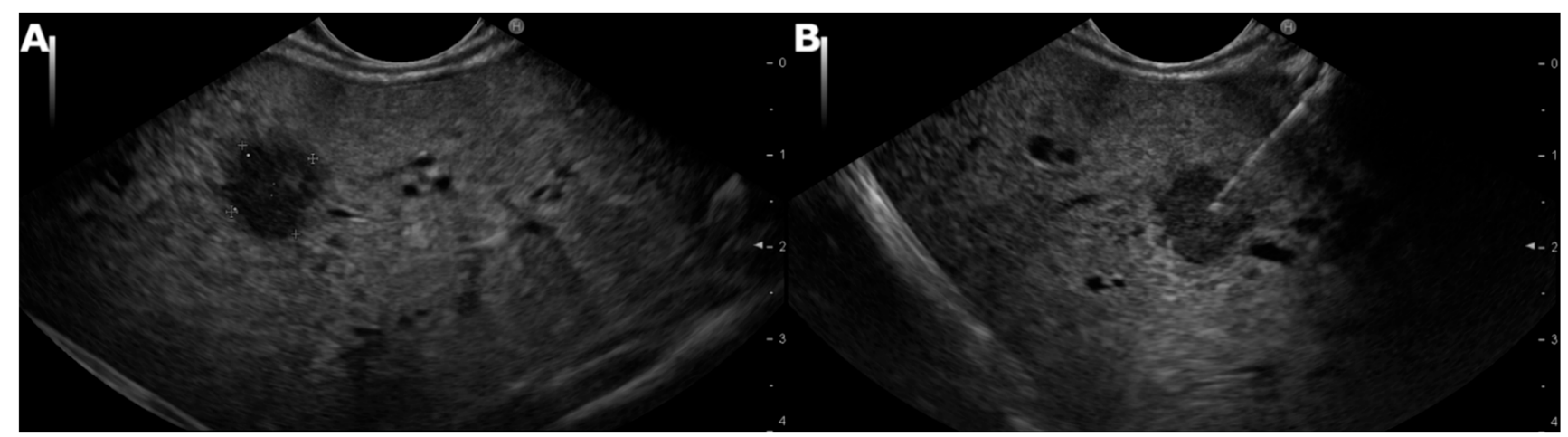

Figure 1. (A) Linear echoendoscope showing a focal lesion in the right lobe of the liver. (B) Linear echoendoscope showing fine-needle biopsy of the focal lesion in the right lobe of the liver.

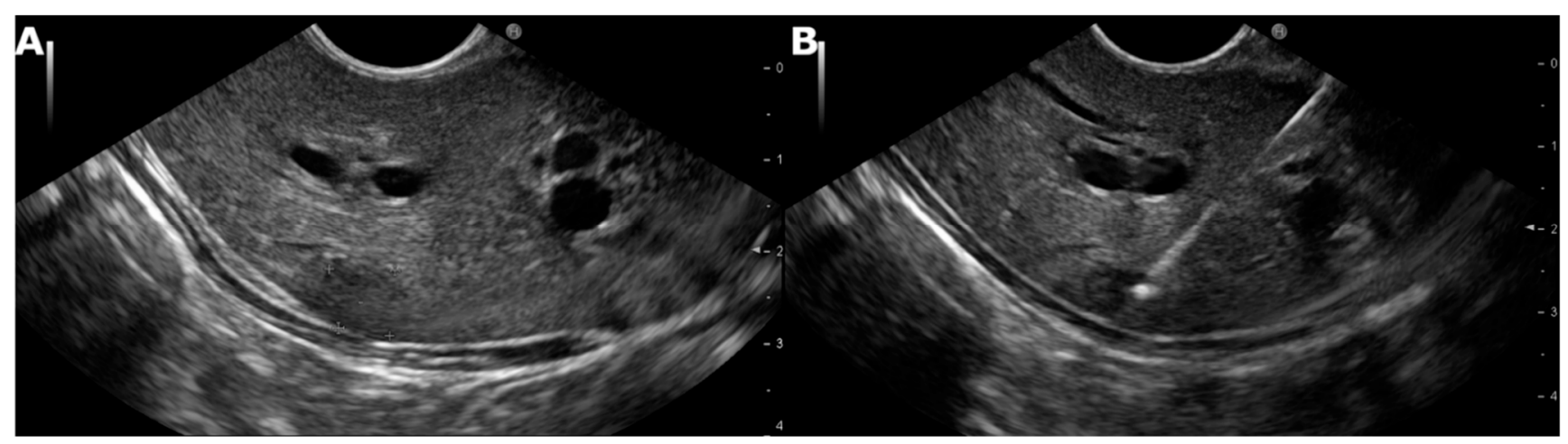

Figure 2. (A) Linear echoendoscope showing a focal lesion in the left lobe of the liver in segment II. (B) Linear echoendoscope showing fine-needle biopsy of the focal lesion in the left lobe of the liver in segment II.

Under EUS-guidance, the needle was advanced into the nodule/liver parenchyma and 10-20 to and from movements were performed while the stylet was slowly retrieved (slow-pull technique). 
Patients were continuously monitored during the procedure by a board-certified anesthesiologist with an automated non-invasive blood pressure device, electrocardiogram tracing and pulse oximetry to evaluate vital signs. Depending on complexity of the procedure and comorbidity, patients were either hospitalized for observation for $24 \mathrm{~h}$ or had the procedure in the day hospital. In both cases, the monitoring protocol was the same regardless of setting.

\section{3. $P C-L B$}

PC-LBs were performed with patients in supine position under local anesthesia. All percutaneous biopsies were performed after an injection of $2 \%$ lidocaine solution using a 25gauge needle into the subcutaneous tissue and up to the liver capsule. No pre-procedure antibiotics were administered. A 16-gauge biopsy needle (Biopince ${ }^{\circledR}$, Argon Medical Devices, Frisco, TX, USA) was inserted into the liver parenchyma under ultrasoundguidance. One core biopsy specimen was obtained, with a second pass performed only if the first pass yielded no specimen.

\subsection{Outcomes}

All specimens were collected in $10 \%$ formalin and sent to the laboratory for processing. The pathologist evaluating the LB specimen was blinded to the method adopted for performing LB (Figure 3).

Primary outcome was diagnostic adequacy rate, defined as the proportion of patients deemed to have adequate samples for histological diagnosis. Secondary outcome was diagnostic accuracy, defined as true positive + true negative divided by total number of patients. The gold standard for diagnosis was considered surgery or clinical follow-up for at least 6 months. Given the absence of a reliable gold standard for diagnosis, patients undergoing LB due to parenchymal disease were excluded from the accuracy analysis.

We also measured the total sample length (TSL) and the number of complete portal tracts (CPTs), where a CPT was defined as the presence of all 3 portal structures (portal vein, hepatic artery, and bile duct) in the sample. Procedural duration and procedure-related severe adverse events were also compared. For EUS-guided biopsy, procedural duration was defined as the time taken to procure the sample after identifying the lesion in the case of focal lesions, or as the time taken to procure two samples after identifying the left or right lobe of liver in the case of parenchymal disease. For the percutaneous biopsy method, this outcome was defined as the time from injection of lidocaine to successful procurement of the liver biopsy specimen.

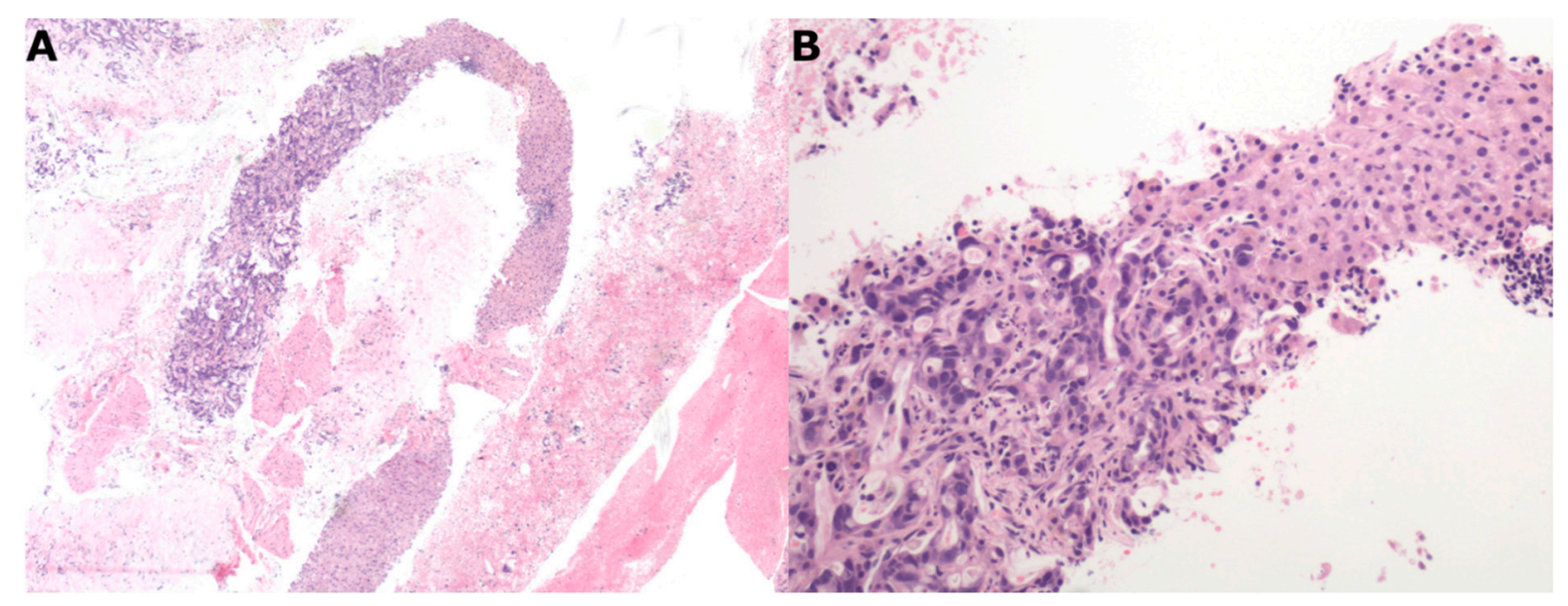

Figure 3. Liver metastasis from ductal adenocarcinoma of the pancreas. (A) $4 \mathrm{~mm}$ needle biopsy of a liver focal lesion with a representative area of adenocarcinoma occupying about $40 \%$ of the biopsy (upper left side) $(4 \times$, EE). (B) At higher magnification, adenocarcinoma cell aggregates (left side) replacing normal hepatocytes (right side) $(20 \times, \mathrm{EE})$. 


\subsection{Statistical Analysis}

Categorical variables were reported as the number of cases and percentage, while differences between groups were compared using the Chi-square test. Continuous variables were expressed as median and interquartile (1st-3rd) range (IQR) and differences between groups were explored by the Mann-Whitney test. All analyses were 2-tailed, and the threshold of significance was assessed at $<0.05$. Subgroup analysis according to indication to LB (whether focal lesion or parenchymal disease) was performed. The statistical analysis was run using the MatchIt package in R Statistical Software 3.0.2 (Foundation for Statistical Computing, Vienna, Austria).

\section{Results}

\subsection{Patients}

During the study period, baseline characteristics of the whole study population of 116 patients who underwent liver biopsy are reported in Table 1. Fifty-four patients underwent EUS-guided LB (Group 1) and 62 underwent PC-LB (Group 2).

Table 1. Baseline Patient Characteristics.

\begin{tabular}{|c|c|c|c|}
\hline & $\begin{array}{c}\text { GROUP } 1 \\
\text { EUS-Guided Liver Biopsy } \\
\text { (54 pts) }\end{array}$ & $\begin{array}{c}\text { GROUP } 2 \\
\text { Percutaneous Liver Biopsy } \\
\text { (62 pts) }\end{array}$ & $p$ Value \\
\hline $\begin{array}{l}\text { Age (years) } \\
\text { median (IQR) }\end{array}$ & $56(48,69)$ & $54(45,67)$ & 0.24 \\
\hline $\begin{array}{l}\text { Gender } \\
\text { Male } \\
\text { Female }\end{array}$ & $\begin{array}{l}32(59.2 \%) \\
22(40.8 \%)\end{array}$ & $\begin{array}{l}38(61.2 \%) \\
24(38.8 \%)\end{array}$ & 0.82 \\
\hline $\begin{array}{l}\text { Biopsy } \\
\text { Focal lesion } \\
\text { Parenchymal disease }\end{array}$ & $\begin{array}{l}27(50 \%) \\
27(50 \%)\end{array}$ & $\begin{array}{l}31(50 \%) \\
31(50 \%)\end{array}$ & 1.0 \\
\hline $\begin{array}{l}\text { Lesion size }(\mathrm{mm}) * \\
\text { Median }(\mathrm{IQR})\end{array}$ & $17(11-22)$ & $18(13-23)$ & 0.83 \\
\hline $\begin{array}{c}\text { Liver cirrhosis } \\
\text { yes } \\
\text { no }\end{array}$ & $\begin{array}{l}27(50 \%) \\
27(50 \%)\end{array}$ & $\begin{array}{l}38(61.2 \%) \\
24(38.8 \%)\end{array}$ & 0.82 \\
\hline $\begin{array}{l}\text { Total bilirubin }(\mathrm{mg} / \mathrm{dL}) \\
\text { median (IQR) }\end{array}$ & $0.7(0.5-1.4)$ & $1.1(0.5-1.5)$ & 0.45 \\
\hline $\begin{array}{l}\text { Aspartate aminotransferase (UI/dL) } \\
\text { median (min, max) }\end{array}$ & $31.3(15-260)$ & $42.4(25-302)$ & 0.58 \\
\hline $\begin{array}{l}\text { Alanine aminotransferase (UI/dL) } \\
\text { Median (min, max) }\end{array}$ & $44.3(21-320)$ & $52.7(28.3-401)$ & 0.14 \\
\hline $\begin{array}{l}\text { Platelet Count }\left(\times 10^{9} / \mathrm{L}\right) \\
\text { Median }(\min , \max )\end{array}$ & $210(133-301)$ & $298(124-322)$ & 0.33 \\
\hline $\begin{array}{l}\text { International normalized ratio } \\
\text { Median (min, max) }\end{array}$ & $0.9(0.7-1.2)$ & $1.2(0.9-1.3)$ & 0.73 \\
\hline $\begin{array}{l}\text { Site of liver biopsy * } \\
\text { Right lobe } \\
\text { Left lobe }\end{array}$ & $\begin{array}{l}17(62.9 \%) \\
10(37.1 \%)\end{array}$ & $\begin{array}{l}19(61.2 \%) \\
12(38.8 \%)\end{array}$ & 1.0 \\
\hline
\end{tabular}


Table 1. Cont.

\begin{tabular}{|c|c|c|c|}
\hline & $\begin{array}{c}\text { GROUP } 1 \\
\text { EUS-Guided Liver Biopsy } \\
\text { (54 pts) }\end{array}$ & $\begin{array}{c}\text { GROUP } 2 \\
\text { Percutaneous Liver Biopsy } \\
\text { (62 pts) }\end{array}$ & $p$ Value \\
\hline \multicolumn{4}{|l|}{ Liver segments * } \\
\hline II & 4 & 5 & \multirow{7}{*}{$p$ value: 0.89} \\
\hline III & 6 & 7 & \\
\hline IV & 5 & 5 & \\
\hline V & 5 & 6 & \\
\hline VI & 6 & 6 & \\
\hline VII & 0 & 1 & \\
\hline VIII & 1 & 1 & \\
\hline \multicolumn{4}{|l|}{ EUS Needle } \\
\hline 19G FNA & 29 & & \multirow{5}{*}{-} \\
\hline 25G ProCore ${ }^{\circledR}$ & 1 & & \\
\hline 22G SharkCore ${ }^{\circledR}$ & 8 & - & \\
\hline 25G SharkCore ${ }^{\circledR}$ & 11 & & \\
\hline 25G Acquire ${ }^{\circledR}$ & 5 & & \\
\hline
\end{tabular}

Values are expressed as number (percentage) or median (interquartile ranges) where specified; * Patients with focal lesions; Abbreviations: EUS, Endoscopic Ultrasound; IQR, Interquartile Range.

Indication to EUS in group 1 was diagnostic work-up of focal pancreatic masses in 28 patients $(51.9 \%)$, characterization of pancreatic cystic lesions in 18 patients (33.3\%), suspected autoimmune pancreatitis in 4 patients (7.4\%), and sampling of upper GI subepithelial lesions in 4 patients $(7.4 \%)$.

As reported in Table 1, no difference was observed in the comparison between the two study groups. Median age was 56 years (IQR 48-69) in group 1 and 54 years (45-67) in group $2(p=0.24)$. Thirty-two $(59.2 \%)$ patients in the EUS-LB group and 38 patients $(61.2 \%)$ in the PC-LB group were male $(p=0.82)$, and indication to LB was due to parenchymal disease in $50 \%$ of patients whereas the other half of the sample size underwent LB due to focal liver lesions $(p=1.0)$. Median size of sampled focal lesions was $17 \mathrm{~mm}(11-22)$ and $18 \mathrm{~mm}(13-23)$ in the two groups, respectively $(p=0.83)$.

Participants with liver cirrhosis was present in 27 patients in group $1(50 \%)$ and in 38 patients $(61.2 \%)$ in group $2(p=0.82)$. No difference was registered in terms of liver function tests (total bilirubin $p=0.45$, aspartate aminotransferase $p=0.58$, alanine aminotransferase $p=0.14$, platelet count $p=0.33$, international normalized ratio $p=0.73$ ).

Biopsy was performed in the right lobe of the liver in 17 patients with focal lesions $(62.9 \%)$ in the EUS-LB group and in 19 patients $(61.2 \%)$ in the PC-LB group $(p=1.0)$. Moreover, no difference in terms of liver segments sampled was observed ( $p=0.89)$.

In the EUS-LB group, 19G FNA was used in 29 patients, 25G ProCore ${ }^{\circledR}$ in 1 patient, 22G SharkCore ${ }^{\circledR}$ in 8 patients, 25G SharkCore ${ }^{\circledR}$ in 11 patients, and 25G Acquire ${ }^{\circledR}$ in 5 subjects. Parenchymal biopsies were performed using a $19 \mathrm{G}$ needle in $25(92.6 \%)$ cases and a $22 \mathrm{G}$ needle in $2(7.4 \%)$ cases. Focal lesions were sampled using a $19 \mathrm{G}$, a $22 \mathrm{G}$ and a $25 \mathrm{G}$ needle in $4(14.8 \%), 6(22.2 \%)$, and 17 (63\%) cases, respectively. A 25G needle was usually used to sample small focal lesions. The median number of passes was 2 (1-2) in EUS-LB group and 1 (1-1) in the PC-LB group.

\subsection{Outcomes}

A detailed list of study outcomes is reported in Table 2. Diagnostic adequacy rate was slightly superior in the PC-LB group (100\% vs. $94.4 \%)$ without reaching the significance threshold $(p=0.74)$. 
Table 2. Study outcomes.

\begin{tabular}{|c|c|c|c|}
\hline & $\begin{array}{c}\text { GROUP } 1 \\
\text { EUS-Guided Liver Biopsy } \\
\text { (54 pts) }\end{array}$ & $\begin{array}{c}\text { GROUP } 2 \\
\text { Percutaneous Liver Biopsy } \\
\text { (62 pts) }\end{array}$ & $p$ Value \\
\hline $\begin{array}{l}\text { Total length of specimen (mm) } \\
\text { median (IQR) }\end{array}$ & $18.5(10.1-22.4)$ & $27.4(21-29)$ & 0.02 \\
\hline $\begin{array}{l}\text { No. of complete portal tracts } \\
\text { Median (IQR) }\end{array}$ & $18.5(10-23.2)$ & $21(11-24)$ & 0.09 \\
\hline Diagnostic adequacy & $51(94.4 \%)$ & $62(100 \%)$ & 0.74 \\
\hline Diagnostic accuracy * & $24(88.8 \%)$ & $31(100 \%)$ & 0.82 \\
\hline $\begin{array}{l}\text { Final diagnosis } \\
\text { Hepatocellular carcinoma } \\
\text { Liver metastasis } \\
\text { Chronic hepatitis } \\
\text { NASH } \\
\text { Normal liver }\end{array}$ & $\begin{array}{c}12 \\
14 \\
17 \\
4 \\
7\end{array}$ & $\begin{array}{c}16 \\
10 \\
24 \\
4 \\
8\end{array}$ & 0.74 \\
\hline $\begin{array}{l}\text { Procedural duration (mins) } \\
\text { median (min, max) }\end{array}$ & $7(5-11)$ & $1(1-3)$ & $<0.001$ \\
\hline Procedure-related severe adverse events & $0(0 \%)$ & $0(0 \%)$ & 1.0 \\
\hline
\end{tabular}

Values are expressed as number (percentage) or median (interquartile ranges) where specified; ${ }^{*}$ Patients with focal lesions; Abbreviations: EUS, Endoscopic Ultrasound; IQR, Interquartile Range. The bold indicates results with statistical significance.

Median TSL was significantly greater in the PC-LB group (27.4 mm, IQR 21-29) compared to the EUS-LB group $(18.5,10.1-22.4 ; p=0.02)$. The number of complete portal tracts was superior in the PC-LB group, although the difference only approached the significance threshold (21, 11-24 in the PC-LB group versus 18.5, 10-23.2 in the EUS-LB group; $p=0.09$ ).

Diagnostic accuracy rate in patients with focal liver lesions was $88.8 \%$ in the EUS-LB group and $100 \%$ in the PC-LB arm $(p=0.82)$. Final diagnosis was hepatocellular carcinoma in 28 patients (12 in group 1 and 16 in group 2 ), liver metastases in 24 patients (14 in the EUS-LB and 10 in the PC-LB group) and 41 patients were diagnosed with chronic hepatitis (17 in the EUS-LB and 24 in the PC-LB group). Non-alcoholic steatohepatitis was detected in 8 patients (4 in each group) whereas an absence of hepatic disease was registered in 15 subjects (7 in the EUS-LB and 8 in the PC-LB group). Overall, no difference in terms of pathologic conditions diagnosed was observed between the two groups $(p=0.74)$.

EUS-LB was a significantly longer procedure (7 min, 5-11 versus $1 \mathrm{~min}, 1-3$ of PCLB; $p<0.001$ ) and no evidence of severe adverse events was observed in any of the study groups.

\subsection{Subgroup Analysis}

As described in Table 3, results of the main analysis were confirmed in the subgroup analysis performed according to the indication to LB (parenchymal disease versus focal lesion). 
Table 3. Subgroup analysis according to indication to biopsy (parenchymal disease versus focal lesion).

\begin{tabular}{|c|c|c|c|c|}
\hline Variable & Subgroup & $\begin{array}{c}\text { GROUP } 1 \\
\text { EUS-Guided Liver } \\
\text { Biopsy } \\
\text { (54 pts) }\end{array}$ & $\begin{array}{c}\text { GROUP } 2 \\
\text { Percutaneous Liver } \\
\text { Biopsy } \\
\text { (62 pts) }\end{array}$ & $p$ Value \\
\hline \multirow{2}{*}{$\begin{array}{l}\text { Total length of specimen } \\
(\mathrm{mm})\end{array}$} & Parenchymal disease & $21.5(14.1-25.4)$ & $30.2(23-34)$ & 0.008 \\
\hline & Focal lesion & $10(8.9-21.3)$ & $15(11.3-25.8)$ & 0.03 \\
\hline \multirow{2}{*}{ No. of complete portal tracts } & Parenchymal disease & $18.5(10-23.2)$ & $21(11-24)$ & 0.09 \\
\hline & Focal lesion & - & - & - \\
\hline \multirow{2}{*}{ Diagnostic adequacy } & Parenchymal disease & $26(96.2 \%)$ & $31(100 \%)$ & 0.88 \\
\hline & Focal lesion & $25(92.2 \%)$ & $31(100 \%)$ & 0.79 \\
\hline \multirow{2}{*}{ Diagnostic accuracy } & Parenchymal disease & - & - & - \\
\hline & Focal lesion & $24(88.8 \%)$ & $31(100 \%)$ & 0.82 \\
\hline \multirow{2}{*}{ Procedural duration (mins) } & Parenchymal disease & $7(5-10)$ & $1(1-3)$ & $<0.001$ \\
\hline & Focal lesion & $7(5-12)$ & $1(1-4)$ & $<0.001$ \\
\hline
\end{tabular}

Values are expressed as number (percentage) in the case of categorical outcomes or median (interquartile ranges) in the case of continuous variables; Abbreviations: EUS, Endoscopic Ultrasound. The bold indicates results with statistical significance.

Median TSL was $10 \mathrm{~mm}(8.9-21.3)$ and $15 \mathrm{~mm}$ (11.3-25.8) in the EUS-LB and PC-LB group, respectively $(p=0.03)$, in patients with focal lesions whereas total sample length was $21.5 \mathrm{~mm}(14.1-25.4)$ and $30.2 \mathrm{~mm}(23-34)$ in the two groups, respectively $(p=0.008)$, in patients with parenchymal disease.

Diagnostic adequacy was $96.2 \%$ in the EUS-LB group and 100\% in the PC-LB group in the case of parenchymal disease $(p=0.88)$; likewise, adequacy rate was $92.2 \%$ in the EUS-LB and $100 \%$ in the PC-LB group in patients with focal lesions $(p=0.79)$. Moreover, EUS-LB resulted significantly longer than PC-LB in both subgroups $(p<0.001)$.

\section{Discussion}

Liver biopsy represents the gold standard method for assessment of fibrosis severity in chronic liver disease [19]. Tissue sampling is used to determine the degree or stage of fibrosis. However, traditional percutaneous liver biopsy techniques are limited by the risk of potentially serious complications, inter-observer variations, and sampling errors, leading to false negative diagnosis [20,21]. Furthermore, percutaneous liver biopsy is associated with post-procedural pain.

EUS-guided LB is well known to achieve optimal core histology samples. Furthermore, EUS-LB has the advantage of being able to obtain multiple liver passes quickly and safely from both lobes of the liver.

This decreases the histologic variability through sampling different areas of the liver in addition to providing imaging assessment of other intra-abdominal organs.

However, there is still no consensus on what an 'adequate' liver biopsy actually represents. AASLD guidelines suggest that adequate liver biopsy specimens be at least $1.5 \mathrm{~cm}$ in length and contain more than 11 portal tracts. The Royal College of Pathologists defines adequacy as being greater than $1 \mathrm{~cm}$ in length and containing at least 6 portal tracts $[22,23]$.

Although preliminary studies have not shown any significant difference between EUS-LB and PC-LB, a recent RCT found a clear superiority of PC-LB over EUS-LB in terms of optimal core procurement based on the aforementioned criteria [18]. This randomized clinical trial demonstrated that the PC-LB method yielded significantly more optimal specimens, defined as specimens with a length of $25 \mathrm{~mm}$ or greater and the presence of at least 11 complete portal tracts (CPT), compared with the EUS-guided method (57.9\% vs. $23.8 \%, p=0.028)$. While the PC-LB was associated with greater post-procedural pain, it was less costly (US\$1824 vs. US\$3240, $p<0.001$ ) [18].

Currently, the $16 \mathrm{G}$ Biopince ${ }^{\circledR}$ needle is the standard-of-care device for performing PC biopsies. It integrates a triaxial core, cut and capture system with an automated firing 
sequence. This enables the operator to procure of a full core of tissue alongside the whole diameter and length of the needle (full core biopsy needles). On the contrary, large calibre EUS-FNB needles are not larger than $19 \mathrm{G}$ in diameter. These needles' geometries are Franseen, Fork-tip, Menghini or Reverse bevel in design, and have two to three cutting edges or side holes at the tip to facilitate core tissue procurement $[24,25]$. Therefore, the EUS-FNB devices are not full core biopsy needles.

Additionally, compared with transgastric or transduodenal biopsies where the FNB needle tip is partially flexed as it is moves back and forth in different trajectories within a target organ, the PC method uses a single cut motion in a straight plane. These differences were likely responsible for the more favorable diagnostic outcomes of PC-LB, compared to the EUS-LB in the aforementioned trial [18].

Therefore, given the scarce and conflicting evidence on this topic, we decided to perform a retrospective analysis of our series of patients who underwent to EUS-LB and PC-LB in two high-volume Italian centers.

Diagnostic adequacy was slightly superior in PC-LB group (100\% vs. $94.4 \%)$, although this difference was not statistically significant $(p=0.74)$, in accordance with previously published studies $[18,26]$. Our results confirmed the findings of the aforementioned trial with a greater median TSL in the PC-LB group ( $27.4 \mathrm{~mm}$ as compared to $18.5 \mathrm{~mm}$ in the EUS-LB group; $p=0.02$ ).

Similarly, the number of complete portal tracts was superior in the PC-LB, although the difference only approached the significance threshold $(p=0.09)$; the limited sample size in our study may have contributed to a lack of statistical significance and the trend in favor of PC-LB should be confirmed in larger clinical series.

It is worth noting that the current manuscript represents the first comparative series recruiting patients with focal liver lesions, who represented half of the sample size. Subgroup analysis confirmed the above reported results in both subsets of patients; therefore, we can conclude that PC-LB provides higher quality samples even with comparable accuracy and adequacy rates both in patients with parenchymal disease and in the case of focal liver lesions.

Accuracy rates were favorable with both techniques regardless of the final diagnosis, thus pointing out the striking performances of both PC-LB and EUS-LB in several hepatic pathological conditions. As expected, EUS-LB was a significantly longer procedure $(7 \mathrm{~min}$ versus $1 \mathrm{~min} ; p<0.001)$, a further drawback of this technique compared to PC-LB. However, EUS-LB should not compete with PC-LB but play a complementary role and should be considered when EUS is already indicated for different reasons. Thus, patients could benefit from two high-quality evaluations during a single procedure. Moreover, in cases of small liver focal lesions located in positions which are difficult to reach percutaneously, EUS-LB could be considered to be a first line procedure.

Finally, none of the recruited patients experienced serious adverse events with EUS-LB or with the percutaneous approach.

This study has several strengths: first, it is the first series directly comparing EUS-LB and PC-LB in patients with focal liver lesions, unlike previous studies that enrolled only patients with parenchymal liver diseases. Second, all the main diagnostic outcomes were collected with specific pathological parameters such as TSL and the number of CPTs. Third, the multicentricity of the current study allows a reliable reproducibility of our findings.

Nevertheless, our study has some weaknesses. Its main limitation is the retrospective nature of the study which could have led to selection biases. However, the two groups were comparable in terms of all the main baseline parameters; thus, the study groups were perfectly balanced without statistically different clinical and demographic features. In addition, cost considerations were beyond the scope of the present study and could not be addressed. However, it is hypothesized that the cost of EUS-LB may be substantially reduced when coupled with other endoscopic procedures (i.e., diagnostic or surveillance endoscopy). 
Furthermore, it should be noted that the invasive and costly nature of LB along with the risk of adverse events have been responsible for a steady decline in the need for LB in patients with chronic liver disease and focal lesions. In fact, non-invasive measurements of liver stiffness are reliable and robust for assessing liver fibrosis/cirrhosis. These non-invasive methods allow for multiple and repeated assessments which can be safely performed in order to track the kinetics of liver stiffness after viral eradication in HCV patients [27].

Likewise, current guidelines restrict the need for LB in patients with focal lesions only in the case of inconclusive imaging findings $[28,29]$. Therefore, the role of LB remains uncertain in several settings; nevertheless, particularly in the case of focal liver lesions, the need for precise definition of specific biomarkers might reverse this trend and call for more LBs in the future [30-32].

\section{Conclusions}

EUS-LB is an alternative to percutaneous methods for liver biopsy. Our analysis provides robust evidence on the comparison between EUS-LB and PC-LB in patients with parenchymal liver disease and focal liver lesions. Therefore, based on our findings and the results of previous studies, there is no evidence supporting a wide use of EUS-LB. EUS-LB does not appear to be superior to PC-LB, and thus, PC-LB remains the sampling method of choice in this field. Broad prospective randomized trials with cost effective analyses are warranted in order to confirm the results of our analysis.

Author Contributions: Conceptualization, A.F. and S.F.C.; methodology, A.F.; software, A.F.; validation, A.F., M.C.C.B. and L.B.; formal analysis, A.F.; investigation, S.F.C., E.M. and N.M.; resources, A.F.; data curation, A.F., and S.F.C.; writing-original draft preparation, A.F.; writing-review and editing, A.F., S.F.C. and D.R.; visualization, A.F.; supervision, A.F.; project administration, A.F. All authors have read and agreed to the published version of the manuscript.

Funding: This research received no external funding.

Institutional Review Board Statement: Institutional Review Board (IRB) approbation for this retrospective report was obtained. The study was conducted according to the guidelines of the Declaration of Helsinki, and approved by the Institutional Review Board (or Ethics Committee) of University of Foggia.

Informed Consent Statement: Informed consent was obtained from all subjects involved in the study.

Data Availability Statement: The datasets used and/or analyzed during the current study are available from the corresponding author upon request.

Conflicts of Interest: The authors declare no conflict of interest.

\section{References}

1. Singh, S.; Facciorusso, A.; Loomba, R.; Falck-Ytter, Y.T. Magnitude and Kinetics of Decrease in Liver Stiffness After Antiviral Therapy in Patients with Chronic Hepatitis C: A Systematic Review and Meta-analysis. Clin. Gastroenterol. Hepatol. 2018, 16, 27-38.e4. [CrossRef]

2. Facciorusso, A.; Garcia Perdomo, H.A.; Muscatiello, N.; Buccino, R.V.; Wong, V.W.; Singh, S. Systematic review with me-taanalysis: Change in liver stiffness during anti-viral therapy in patients with hepatitis B. Dig. Liver Dis. 2018, 50, 787-794. [CrossRef] [PubMed]

3. Lavian, J.; Thornton, L.; Zybulewski, A.; Kim, E.; Nowakowski, S.; Ranade, M.; Patel, R.; Lookstein, R.; Fischman, A.; Bishay, V. Safety of percutaneous versus transjugular liver biopsy: A propensity score matched analysis. Eur. J. Radiol. 2020, $133,109399$. [CrossRef]

4. Hollerbach, S.; Willert, J.; Topalidis, T.; Reiser, M.; Schmiegel, W.-H. Endoscopic Ultrasound-Guided Fine-Needle Aspiration Biopsy of Liver Lesions: Histological and Cytological Assessment. Endoscopy 2003, 35, 743-749. [CrossRef]

5. Baran, B.; Kale, S.; Patil, P.; Kannadath, B.; Ramireddy, S.; Badillo, R.; DaVee, R.T.; Thosani, N. Endoscopic ultrasound-guided parenchymal liver biopsy: A systematic review and meta-analysis. Surg. Endosc. 2020. [CrossRef] [PubMed]

6. $\quad$ Renelus, B.D.; Jamorabo, D.S.; Boston, I.; Briggs, W.M.; Poneros, J.M. Endoscopic Ultrasound-Guided Fine Needle Biopsy Needles Provide Higher Diagnostic Yield Compared to Endoscopic Ultrasound-Guided Fine Needle Aspiration Needles When Sampling Solid Pancreatic Lesions: A Meta-Analysis. Clin. Endosc. 2021, 54, 261-268. [CrossRef] 
7. Mohan, B.P.; Shakhatreh, M.; Garg, R.; Ponnada, S.; Adler, D.G. Efficacy and safety of EUS-guided liver biopsy: A systematic review and meta-analysis. Gastrointest. Endosc. 2019, 89, 238-246.e3. [CrossRef]

8. Crinò, S.F.; Ammendola, S.; Meneghetti, A.; Bernardoni, L.; Bellocchi, M.C.C.; Gabbrielli, A.; Landoni, L.; Paiella, S.; Pin, F.; Parisi, A.; et al. Comparison between EUS-guided fine-needle aspiration cytology and EUS-guided fine-needle biopsy histology for the evaluation of pancreatic neuroendocrine tumors. Pancreatology 2021, 21, 443-450. [CrossRef]

9. Facciorusso, A.; Del Prete, V.; Buccino, V.R.; Purohit, P.; Setia, P.; Muscatiello, N. Diagnostic yield of Franseen and Fork-Tip biopsy needles for endoscopic ultrasound-guided tissue acquisition: A meta-analysis. Endosc. Int. Open 2019, 7, E1221-E1230. [CrossRef]

10. Facciorusso, A.; Wani, S.; Triantafyllou, K.; Tziatzios, G.; Cannizzaro, R.; Muscatiello, N.; Singh, S. Comparative accuracy of needle sizes and designs for EUS tissue sampling of solid pancreatic masses: A network meta-analysis. Gastrointest. Endosc. 2019, 90, 893-903. [CrossRef] [PubMed]

11. Crinò, S.F.; Le Grazie, M.; Manfrin, E.; Conti Bellocchi, M.C.; Bernardoni, L.; Granato, A.; Locatelli, F.; Parisi, A.; Di Stefano, S.; Frulloni, L.; et al. Randomized trial comparing fork-tip and side-fenestrated needles for EUS-guided fi-ne-needle biopsy of solid pancreatic lesions. Gastrointest. Endosc. 2020, 92, 648-658. [CrossRef]

12. Larghi, A.; Rimbaş, M.; Crino, S.F.; Gasbarrini, A.; Costamagna, G.; Scarpa, A. EUS-guided fine-needle tissue acquisition for solid pancreatic lesions: Finally moving from fine-needle aspiration to fine-needle biopsy? Endosc. Ultrasound 2018, 7, 137-140. [CrossRef]

13. Crinò, S.F.; Di Mitri, R.; Nguyen, N.Q.; Tarantino, I.; de Nucci, G.; Deprez, P.H.; Carrara, G.; Kitano, M.; Shami, V.M.; FernándezEsparrach, G.; et al. EUS-guided fine-needle biopsy with or without rapid on-site evaluation for diagnosis of solid pancreatic lesions: A randomized controlled non-inferiority trial. Gastroenterology 2021. [CrossRef] [PubMed]

14. Facciorusso, A.; Sunny, S.P.; Del Prete, V.; Antonino, M.; Muscatiello, N. Comparison between fine-needle biopsy and fi-ne-needle aspiration for EUS-guided sampling of subepithelial lesions: A meta-analysis. Gastrointest. Endosc. 2020, 91, 14-22. [CrossRef]

15. Bhogal, N.; Lamb, B.; Arbeiter, B.; Malik, S.; Sayles, H.; Lazenby, A.J.; Chandan, S.; Dhaliwal, A.; Singh, S.; Bhat, I. Safety and adequacy of endoscopic ultrasound-guided random liver biopsy in comparison with transjugular and percutaneous ap-proaches. Endosc. Int. Open 2020, 8, E1850-E1854.

16. Pineda, J.J.; Diehl, D.L.; Miao, C.L.; Johal, A.S.; Khara, H.S.; Bhanushali, A.; Chen, E.Z. EUS-guided liver biopsy provides diagnostic samples comparable with those via the percutaneous or transjugular route. Gastrointest. Endosc. 2016, 83, 360-365. [CrossRef] [PubMed]

17. Shuja, A.; Alkhasawneh, A.; Fialho, A.; Shukri, A.; Harris, C.; Smotherman, C.; Malespin, M.; De Melo, S.W. Comparison of EUS-guided versus percutaneous and transjugular approaches for the performance of liver biopsies. Dig. Liver Dis. 2019, 51, 826-830. [CrossRef]

18. Bang, J.Y.; Ward, T.J.; Guirguis, S.; Krall, K.; Contreras, F.; Jhala, N.; Navaneethan, U.; Hawes, R.H.; Varadarajulu, S. Radi-ologyguided percutaneous approach is superior to EUS for performing liver biopsies. Gut 2021. [CrossRef]

19. The French METAVIR Cooperative Study Group. Intraobserver and interobserver variations in liver biopsy interpretation in patients with chronic hepatitis C. Hepatology 1994, 20, 15-20. [CrossRef]

20. Bedossa, P.; Poynard, T. An algorithm for the grading of activity in chronic hepatitis C. The METAVIR Cooperative Study Group. Hepatology 1996, 24, 289-293. [CrossRef]

21. Bedossa, P.; Dargere, D.; Paradis, V. Sampling variability of liver fibrosis in chronic hepatitis C. Hepatology 2003, 38, $1449-1457$. [CrossRef]

22. Piccinino, F.; Sagnelli, E.; Pasquale, G.; Giusti, G.; Battocchia, A.; Bernardi, M.; Bertolazzi, R.; Bianchi, F.; Brunelli, E.; Budillon, G.; et al. Complications following percutaneous liver biopsy: A multicentre retrospective study on 68276 biopsies. J. Hepatol. 1986, 2, 165-173. [CrossRef]

23. Rockey, D.C.; Caldwell, S.H.; Goodman, Z.D.; Nelson, R.C.; Smith, A.D. American Association for the Study of Liver Diseases. Liver biopsy. Hepatology 2009, 49, 1017-1044. [CrossRef]

24. Neuberger, J.; Patel, J.; Caldwell, H.; Davies, S.; Hebditch, V.; Hollywood, C.; Hubscher, S.; Karkhanis, S.; Lester, W.; Roslund, N.; et al. Guidelines on the use of liver biopsy in clinical practice from the British Society of Gastroenterology, the Royal College of Radiologists and the Royal College of Pathology. Gut 2020, 69, 1382-1403. [CrossRef]

25. Tang, S.-J.; Vilmann, A.S.; Saftoiu, A.; Wang, W.; Streba, C.T.; Fink, P.P.; Griswold, M.; Wu, R.; Dietrich, C.F.; Jenssen, C.; et al. EUS Needle Identification Comparison and Evaluation study (with videos). Gastrointest. Endosc. 2016, 84, 424-433.e2. [CrossRef] [PubMed]

26. Di Leo, M.; Crinò, S.F.; Bernardoni, L.; Rahal, D.; Auriemma, F.; Correale, L.; Donato, G.; Massidda, M.; Anderloni, A.; Manfrin, E.; et al. EUS-guided core biopsies of pancreatic solid masses using a new fork-tip needle: A multicenter prospective study. Dig. Liver Dis. 2019, 51, 1275-1280. [CrossRef]

27. Facciorusso, A.; Del Prete, V.; Turco, A.; Buccino, R.V.; Nacchiero, M.C.; Muscatiello, N. Long-term liver stiffness assessment in hepatitis C virus patients undergoing antiviral therapy: Results from a 5-year cohort study. J. Gastroenterol. Hepatol. 2018, 33, 942-949. [CrossRef]

28. Heimbach, J.K. Overview of the Updated AASLD Guidelines for the Management of HCC. Gastroenterol. Hepatol. 2017, 13, 751-753.

29. Aghemo, A. Update on HCC Management and Review of the New EASL Guidelines. Gastroenterol. Hepatol. 2018, 14, $384-386$. 
30. Facciorusso, A.; Licinio, R.; Carr, B.I.; Di Leo, A.; Barone, M. MEK 1/2 inhibitors in the treatment of hepatocellular carcinoma. Expert Rev. Gastroenterol. Hepatol. 2015, 9, 993-1003. [CrossRef]

31. Jang, S.Y.; Tak, W.Y.; Park, S.Y.; Kweon, Y.-O.; Lee, Y.R.; Kim, G.; Hur, K.; Han, M.-H.; Lee, A.W.K. Diagnostic Efficacy of Serum Mac-2 Binding Protein Glycosylation Isomer and Other Markers for Liver Fibrosis in Non-Alcoholic Fatty Liver Diseases. Ann. Lab. Med. 2021, 41, 302-309. [CrossRef] [PubMed]

32. Eslam, M.; Wong, G.L.-H.; Hashem, A.M.; Chan, H.L.-Y.; Nielsen, M.J.; Leeming, D.J.; Chan, A.W.-H.; Chen, Y.; Duffin, K.L.; Karsdal, M.; et al. A Sequential Algorithm Combining ADAPT and Liver Stiffness Can Stage Metabolic-Associated Fatty Liver Disease in Hospital-Based and Primary Care Patients. Am. J. Gastroenterol. 2021, 116, 984-993. [CrossRef] [PubMed] 